\section{JTI}

JOURNAL OF

TRAUMA AND INJURY

\title{
Analysis of Risk Factors for Infection in Orthopedic Trauma Patients
}

\author{
Gi Ho Moon, M.D., Jae-Woo Cho, M.D., Beom Soo Kim, M.D., \\ Do Hyun Yeo, M.D., Jong-Keon Oh, M.D., Ph.D. \\ Department of Orthopedic Surgery, Guro Hospital, Korea University Medical Center, \\ Seoul, Korea
}

Received: June 19, 2018

Revised: October 16, 2018

Accepted: October 18, 2018

\section{Correspondence to}

Jae-Woo Cho, M.D.

Department of Orthopedic Surgery, Guro Hospital, Korea University Medical Center, 148 Gurodong-ro, Guro-gu, Seoul 08308, Korea

Tel: $+82-2-2626-1178$

Fax: +82-2-863-1684

E-mail: jeus1103@gmail.com

Purpose: We perform an analysis of infection risk factors for fracture patients and confirm that the risk factors reported in previous studies increase the risk of actual infection among fractured patients. In addition, injury severity score (ISS) which is used as an evaluation tool for morbidity of trauma patients, confirms whether there is a relationship with infection after orthopedic fracture surgery.

Methods: We retrospectively reviewed 1,818 patients who underwent fixation surgery at orthopedic trauma team, focused trauma center from January 1, 2015 to December 31, 2017. Thirty-five patients were infected after fracture surgery. We analyzed age, sex, open fracture criteria based on Gustilo-Aderson classification 3b, anatomical location (upper extremity or lower extremity) of fracture, diabetes, smoking, ISS.

Results: Of 1,818 patients, 35 (1.9\%) were diagnosed with postoperative infection. Of the 35 infected patients, nine (25.7\%) were female and five (14.0\%) were upper extremity fractures. Three (8.6\%) were diagnosed with diabetes and eight $(22.8 \%)$ were smokers. Thirteen (37.1\%) had ISS less than nine points and six (17.1\%) had ISS 15 points or more. Of 1,818 patients, 80 had open fractures. Surgical site infection were diagnosed in $12(15.0 \%)$ of 80 . And nine of 12 were checked with Gustilo-Aderson classification $3 \mathrm{~b}$ or more. Linear logistic regression analysis was performed using statistical analysis program Stata 15 (Stata Corporation, College Station, TX, USA). In addition, independent variables were logistic regression analyzed individually after Propensity scores matching. In all statistical analyzes, only open fracture was identified as a risk factor.

Conclusions: The risk factors for infection in fracture patients were found to be significantly influenced by open fracture rather than the underlying disease or anatomical feature of the patient. In the case of ISS, it is considered that there is a limitation. It is necessary to develop a new scoring system that can appropriately approach the morbidity of fracture trauma patients.

Keywords: Fracture; Infection; Risk factor; ISS 


\section{INTRODUCTION}

It is estimated that infections after metal fixation in factures, occur in $1-4 \%$ of surgical patients depending on facture site and injury severity [1]. The recognition of risk factors is very important as the first step of prevention of infection and diabetes, open fracture, and crushing are well known [2-4].

Various types of evaluation models have been used for the initial evaluation of trauma patients, and injury severity score (ISS) scoring is a representative trauma severity score system for evaluating systemic trauma [5-7]. Since its introduction in 1974 by Baker et al. [8], clinical utility has been acknowledged and has been used as a value criterion to quantify anatomic severity to quantification. However, there is no data on the clinical significance of ISS scoring in orthopedic fracture patients, which accounts for a large proportion of the patients in the emergency room $[6,9]$.

We perform an analysis of infection risk factors for fracture patients and confirm that the risk factors reported in previous studies increase the risk of actual infection among fractured patients. In addition, ISS, which is used as an evaluation tool for morbidity of trauma patients, confirms whether there is a relationship with infection after orthopedic fracture surgery.

\section{METHODS}

We retrospectively reviewed 1,818 patients who underwent internal fixation surgery at an orthopedic trauma team, focused trauma center from January 1, 2015 to December 31, 2017. Thirty-five patients were infected after fracture surgery. We analyzed age, sex, open fracture criteria based on Gustilo-Aderson classification 3b, anatomical location (upper extremity or lower extremity) of fracture, diabetes, smoking.

All patients were followed up for at least 6 months, and infections were defined as cases in which satisfying Centers for Disease Control and Prevention criteria for deep infection. In order to confirm the age distribution after fracture surgery, the distinction was made based on 10 years. The 10-year standard was arbitrarily set. But, statis- tical analysis was performed by continuous variable not based on decade. The Gustilo-Aderson classification $3 \mathrm{~b}$ requires additional operations such as flap for soft tissue treatment and is defined as the criteria for open fracture.

Orthopedic fracture surgery in the anatomical site except for the hand, foot, and spine was evaluated together, and the operation was carried out by two professors and eight fellows dedicated to fracture during the study period. In the case of the operation performed by the fellow, the preoperative plan and the evaluation of the operation were made by two professors, and the level of the operation was kept constant.

The ISS was assessed and recorded daily by an expert nurse worker using the abbreviated injury scale (AIS) 2005: update 2008 as an assessment tool and confirmed once again by field specialists through weekly meetings. Open fractures were classified according to the Gustilo-Aderson classification. Diabetes mellitus is defined as the case of diagnosis before fracture surgery. Smoking was based on 1 pack-year or more. The antibiotics was based on cefazolin. Open fractures were initially treated with additional gentamycin. After bacteria were identified in the surgical field, we consulted an infectious medical specialist to change antibiotics.

Linear logistic regression analysis was performed using statistical analysis program Stata 15 (Stata Corporation, College Station, TX, USA). In addition, independent variables were logistic regression analyzed individually after propensity scores matching (Fig. 1).

\section{RESULTS}

Of the 1,818 patients who underwent total fracture surgery, 35 (1.9\%) had infections, 935 men (51.4\%) and 883 women (48.6\%). Five hundred and sixteen patients (28.4\%) in the upper extremity fracture, 1,302 (71.9\%) in the lower extremity fracture patients. One hundred and nineteen patients underwent anatomically two or more fracture site operations in the AO classification. Patients who underwent two or more sites of fracture surgery were classified based on the anatomical site actually reflected in the ISS score. A total of 1,818 patients underwent 1,954 operations. 

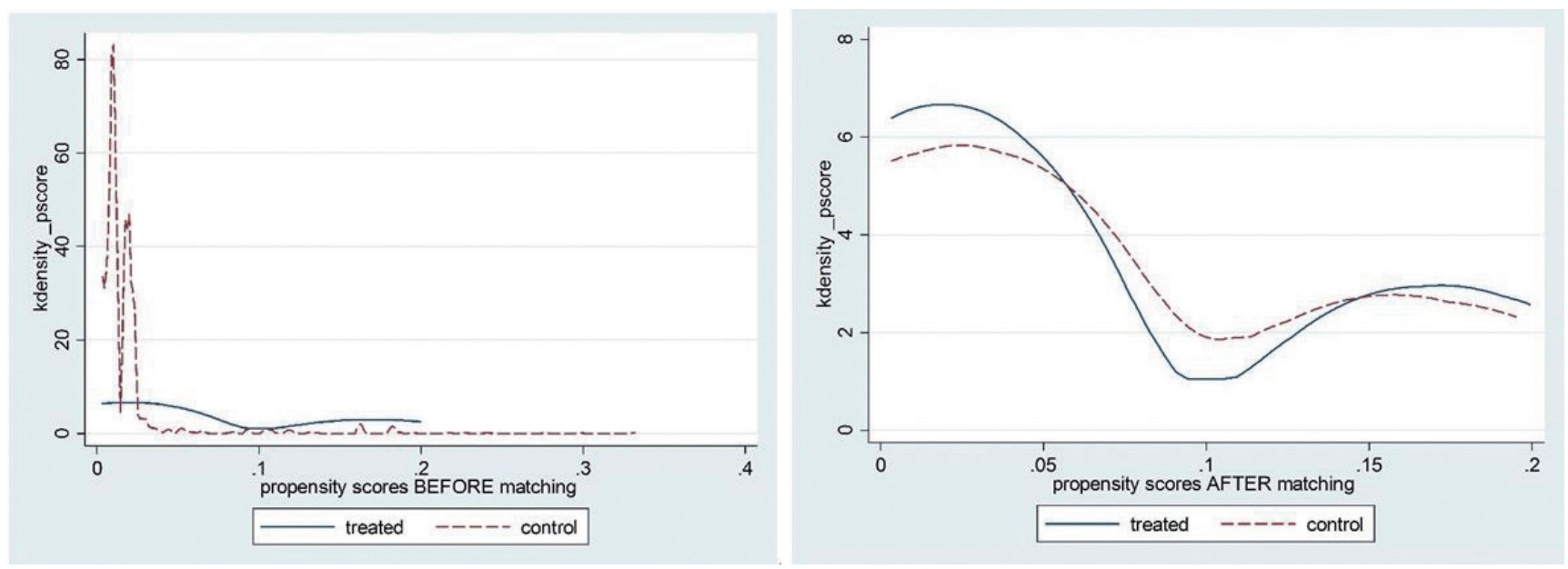

Fig. 1. Propensity scores matching (before and after).

There were five cases of distal femur infection $(7.0 \%$ in total femoral fracture), and the absolute number and rate of infection was the highest. There were 242 (13.3\%) diabetic patients, $455(25.0 \%)$ smokers and $80(4.4 \%)$ open fractures. Of the 35 infected patients, nine $(25.7 \%)$ were female and five (14.0\%) were upper extremity fractures. Three $(8.6 \%)$ were diagnosed with diabetes and eight (22.8\%) were smokers. Thirteen patients (37.1\%) had ISS less than 9 and six patients (17.1\%) had ISS 15 or more (Table 1) [10,11].

Of 80 patients with open fracture, 29 patients were identified with Gustilo-Aderson classification 3b or more. Among them, infection occurred in nine (31.0\%). Of 12 patients who developed open fracture, three patients had primary closure, four patients had flap, five patients had skin graft, but one case failed and finally flap was performed (Table 2).

Only the presence of open fracture was confirmed as a risk factor in both the linear logistic regression analysis and were logistic regression analyzed individually after propensity scores matching. The anatomical site of the fracture and ISS were considered to be correlated to some degree but it did not have statistical power meaning. Sex, age, diabetic mellitus (DM), and smoking were found to be less related to infection (Tables 1,3).

\section{DISCUSSION}

There is no sufficient study on infection after fixation in fracture metal. Most of them are inferred to $1-4 \%$ level based on the result of infection after artificial joint surgery. Most of the risk factors for infection were confirmed in the artificial joint surgery field or in other anatomical region operations [12-16]. Infection after fracture surgery is not the most frequent complication of fracture surgery but sequelae due to complications may be the serious $[17,18]$. However, in the case of fracture surgery, the surgical team is decided according to the anatomical classification, not the specialized trauma team in most medical institutions. Infection after fracture surgery is also being performed most often by orthopedic practitioners who are not experts in fracture trauma who have experience of osteomyelitis. Although the infection progressed to osteomyelitis due to failure to treat infection, only antibiotics were used without appropriate treatment and patients were often left unattended. It is a reality in Korea that limited research has been done due to the relatively low level of interest.

Unlike surgery in other orthopedic areas, fracture surgery should take into account the energy impairment experienced by the patient at the time of injury. In other elective surgeries, there are no additional injuries other than surgical damage, but this is not the case with fracture surgery. Our results also showed that open fractures, 
Table 1. Data characteristic and logistic regression analysis $(n=1,818)$

\begin{tabular}{|c|c|c|c|c|}
\hline & Whole group $(n=1,818)$ & Infection group $(\mathrm{n}=35)$ & Odds ratio & Significance ( $p$ ) \\
\hline Sex & & & 0.591 & 0.228 \\
\hline Male & $935(51.4)$ & $26(74.3)$ & & \\
\hline Female & $883(48.6)$ & $9(25.7)$ & & \\
\hline Age & & & 3.247 & 0.874 \\
\hline $0-19$ & $88(4.8)$ & $1(2.9)$ & & \\
\hline $20-29$ & $155(8.5)$ & $6(17.1)$ & & \\
\hline $30-39$ & $164(9.0)$ & $4(11.4)$ & & \\
\hline $40-49$ & $211(11.6)$ & $2(5.7)$ & & \\
\hline $50-59$ & 309 (16.9) & $9(25.7)$ & & \\
\hline 60-69 & $305(16.8)$ & $6(17.1)$ & & \\
\hline $70-79$ & $343(18.9)$ & $6(17.1)$ & & \\
\hline$\geq 80$ & $243(13.4)$ & $1(2.9)$ & & \\
\hline Open Fx (GA 3b) & $80(4.4)$ & $12(34.3)$ & 13.880 & 0.000 \\
\hline Fracture site & & & 2.487 & 0.069 \\
\hline Upper extremity & $516(28.4)$ & $5(14.3)$ & & \\
\hline Lower extremity & 1,302 (71.9) & $30(85.7)$ & & \\
\hline DM & 242 (13.3) & $3(8.6)$ & 0.606 & 0.646 \\
\hline Smoking & $455(25.0)$ & $8(22.9)$ & 0.888 & 0.824 \\
\hline ISS & & & 1.035 & 0.133 \\
\hline ISS $<9$ & $1,010(55.6)$ & $13(37.1)$ & & \\
\hline $9 \leq \mathrm{ISS}<15$ & $697(38.3)$ & $16(45.7)$ & & \\
\hline $\mid S S \geq 15$ & 111 (6.1) & $6(17.1)$ & & \\
\hline
\end{tabular}

Values are presented as number (\%).

Fx: fracture, GA: Gustilo-Anderson classification, ISS: injury severity score.

Table 2. Incidence of infection by GA classification

\begin{tabular}{|lc|}
\hline & Value \\
\hline GA 1 & $0 / 21(0.0)$ \\
\hline GA 2 $3 a$ & $2 / 18(11.1)$ \\
GA 3b & $1 / 12(8.3)$ \\
GA 3c & $9 / 26(34.6)$ \\
Sum & $0 / 3(0.0)$ \\
\hline
\end{tabular}

Values are presented as number (\%).

GA: Gustilo-Anderson classification.

which can represent the degree of injury at the time of injury, were more significant risk factors than DM, smoking, age, and sex factors. It can be interpreted that the lev- el of energy at the time of injury is absolutely important in the occurrence of infection in fracture surgery and that the risk of relatively known risk factors for elective surgery is not effected.

The ISS score is a representative evaluation tool for the initial evaluation of the trauma patients desired in the emergency room. Recently, the ISS score is widely used as an initial evaluation tool in trauma center operation hospitals. However, there is no definite report on the significance of ISS score in trauma fracture patients [6]. This study began with the ISS score as a tool for assessing the degree of severity of a patient and believed that there would be a statistical association with the incidence of infection that is known to be highly related to severity of injury in the prognosis of fracture $[1,19,20]$. But, 
Table 3. Logistic regression analysis performed after propensity scores matching $(n=70)$

\begin{tabular}{|c|c|c|c|c|}
\hline & Non-Infection group $(n=35)$ & Infection group $(n=35)$ & Odds ratio & Significance $(p)$ \\
\hline Sex & & & 1.000 & 1.000 \\
\hline Male & $26(74.3)$ & $26(74.3)$ & & \\
\hline Female & $9(25.7)$ & $9(25.7)$ & & \\
\hline Age & & & 4.532 & 0.062 \\
\hline 0-19 & $0(0)$ & $1(2.9)$ & & \\
\hline $20-29$ & $1(2.9)$ & $6(17.1)$ & & \\
\hline $30-39$ & $3(8.6)$ & $4(11.4)$ & & \\
\hline $40-49$ & $3(8.6)$ & $2(5.7)$ & & \\
\hline $50-59$ & $9(25.7)$ & $9(25.7)$ & & \\
\hline $60-69$ & $10(28.6)$ & $6(17.1)$ & & \\
\hline 70-79 & $7(20.0)$ & $6(17.1)$ & & \\
\hline$\geq 80$ & $2(5.7)$ & $1(2.9)$ & & \\
\hline Open Fx & & & 3.692 & 0.048 \\
\hline Open & $12(34.3)$ & $12(34.3)$ & & \\
\hline Not-open & $23(65.7)$ & $23(65.7)$ & & \\
\hline Fracture site & & & 0.774 & 0.721 \\
\hline Upper extremity & $5(14.3)$ & $5(14.3)$ & & \\
\hline Lower extremity & $30(85.7)$ & $30(85.7)$ & & \\
\hline DM & & & 1.000 & 1.000 \\
\hline DM & $5(14.3)$ & $3(8.6)$ & & \\
\hline Non-DM & $30(85.7)$ & $32(91.4)$ & & \\
\hline Smoking & & & 0.501 & 0.191 \\
\hline Smoking & $12(34.3)$ & $8(22.9)$ & & \\
\hline Non-smoking & $23(65.7)$ & $27(77.1)$ & & \\
\hline ISS & & & 1.015 & 0.708 \\
\hline ISS $<9$ & $13(37.1)$ & $13(37.1)$ & & \\
\hline $9 \leq 1 \mathrm{ISS}<15$ & $17(48.6)$ & $16(45.7)$ & & \\
\hline $\mathrm{ISS} \geq 15$ & $5(14.3)$ & $6(17.1)$ & & \\
\hline
\end{tabular}

Values are presented as number (\%).

Fx: fracture, DM: diabetic mellitus, ISS: injury severity score.

the AIS 2005: update 2008 ISS score used in this study is different from the score depending on whether there is open fracture or closed fracture, but it is not specific and it is limited to evaluate the damage of multiple fracture patients. Our results also showed that ISS was not statistically related to infection occurrence, which is one of the typical morbidity after fracture surgery. The ISS has the advantage of evaluating not only orthopedic areas but also other related problems, but there are limitations in ortho- pedically expressing multiple fractures, anatomical areas, and specific soft tissue injuries. However, the abbreviated injury scale (AIS) has been specifically coded for the anatomical site and the type of soft tissue injury. The complications of fracture surgery include not only infection but also nonunion and functional impairment. Infection is one of the various morbidity and risk factors for morbidity, which may occur after fracture surgery. We should consider the development of a score summation system 
that can properly express orthopedic complications and treatment results based on the existing AIS coding.

The limitations of our study are limited in the reliability of the results of the study analysis due to the small number of patients in the 35 infected patients who developed in 3 years. The average incidence rate of infected patients is about 1 to $4 \%$, and there is a limit to collect infection cases in one team. In addition, factors such as operative time, bleeding volume, wound morphology, open fracture site microorganisms, time to first operation after injury and other factors known as risk factors for infection are needed for analysis. If sufficient cases are collected, identification of the characteristics of infection by age and anatomical classification should also be performed.

\section{CONCLUSION}

Unlike surgery in other orthopedic areas, the predicting factors for infection in fracture patients were found to be significantly influenced by open fracture rather than the underlying disease or anatomical features of the patient. However, only the correlation with simple open fracture has been confirmed. Therefore, further studies on the cause of open fracture and the mechanism of open fracture are necessary to determine the risk of infection. In the case of ISS, it is considered that there is a limitation on the appropriate morbidity assessment in orthopedic fracture area, and it is necessary to develop a new scoring system that can appropriately approach the morbidity of fracture trauma patients.

\section{REFERENCES}

1. Bonnevialle P. Operative treatment of early infection after internal fixation of limb fractures (exclusive of severe open fractures). Orthop Traumatol Surg Res 2017;103:S67-73.

2. Berkes M, Obremskey WT, Scannell B, Ellington JK, Hymes RA, Bosse $\mathrm{M}$, et al. Maintenance of hardware after early postoperative infection following fracture internal fixation. J Bone Joint Surg Am 2010;92:823-8.

3. Ovaska MT, Mäkinen TJ, Madanat R, Vahlberg T, Hirvensalo E, Lindahl J. Predictors of poor outcomes following deep infection after internal fixation of ankle fractures. Injury 2013;44:1002-6.

4. Tzeng A, Tzeng TH, Vasdev S, Korth K, Healey T, Parvizi J, et al. Treating periprosthetic joint infections as biofilms: key diagnosis and management strategies. Diagn Microbiol Infect Dis 2015;81:192-200.

5. Sutherland AG, Johnston AT, Hutchison JD. The new injury severity score: better prediction of functional recovery after musculoskeletal injury. Value Health 2006;9:24-7.

6. Paffrath T, Lefering R, Flohé S; TraumaRegister DGU. How to define severely injured patients? -- An injury severity score (ISS) based approach alone is not sufficient. Injury 2014;45 Suppl 3:S64-9.

7. Cook A, Weddle J, Baker S, Hosmer D, Glance L, Friedman L, et al. A comparison of the injury severity score and the trauma mortality prediction model. J Trauma Acute Care Surg 2014;76:47-52; discussion 52-3.

8. Baker SP, O’Neill B, Haddon WJ Jr, long WB. The injury severity score: a method for describing patients with multiple injuries and evaluating emergency care. J Trauma 1974;14:187-96.

9. Jamulitrat S, Narong MN, Thongpiyapoom S. Trauma severity scoring systems as predictors of nosocomial infection. Infect Control Hosp Epidemiol 2002;23:268-73.

10. Bedard NA, Dowdle SB, Wilkinson BG, Duchman KR, Gao Y, Callaghan JJ. What is the impact of smoking on revision total knee arthroplasty? J Arthroplasty 2018;33:S172-6.

11. Öztürk AM, Uysal S, Yıldırım Şımşır I, Hüngör H, Işıkgöz Taşbakan M. Hand infection in patients with diabetes: a series of 17 cases and a pooled analysis of the literature. Turk J Med Sci 2018;48:372-7.

12. Papakostidis C, Kanakaris NK, Pretel J, Faour O, Morell DJ, Giannoudis PV. Prevalence of complications of open tibial shaft fractures stratified as per the Gustilo-Anderson classification. Injury 2011;42:1408-15.

13. Rahman WA, Kazi HA, Gollish JD. Results of single stage exchange arthroplasty with retention of well fixed cement-less femoral component in management of infected total hip arthroplasty. World J Orthop 2017;8:264-70.

14. Marmor S, Kerroumi Y. Patient-specific risk factors for infection in arthroplasty procedure. Orthop Traumatol Surg Res 2016;102(1 Suppl):S113-9.

15. Tan TL, Maltenfort MG, Chen AF, Shahi A, Higuera CA, Siqueira $\mathrm{M}$, et al. Development and evaluation of a preoperative risk calculator for periprosthetic joint infection following total joint arthroplasty. J Bone Joint Surg Am 2018;100:777-85. 
16. Casqueiro J, Casqueiro J, Alves C. Infections in patients with diabetes mellitus: a review of pathogenesis. Indian J Endocrinol Metab 2012;16(Suppl1):S27-36.

17. Jackson LC, Pacchiana PD. Common complications of fracture repair. Clin Tech Small Anim Pract 2004;19:168-79.

18. Carpintero P, Caeiro JR, Carpintero R, Morales A, Silva S, Mesa M. Complications of hip fractures: a review. World J Orthop 2014;5:402-11.
19. Alverdy JC, Luo JN. The influence of host stress on the mechanism of infection: lost microbiomes, emergent pathobiomes, and the role of interkingdom signaling. Front Microbiol 2017;8:322.

20. Rochford ET, Richards RG, Moriarty TF. Influence of material on the development of device-associated infections. Clin Microbiol Infect 2012;18:1162-7. 